\title{
Volatile carboxylic acid profiling in physiological fluids: direct injection into a gas chromatograph/mass spectrometer *
}

\author{
Douglas N. Buchanan ** and Jess G. Thoene \\ Department of Pediatrics. University of Michigan, Am Arbor, MI 48109 (USA)
}

(Received July 13th, 1984)

Key nords: GC/MS: Carboxylic acids; Volatile organic acid profiling

\section{Summary}

We present a procedure for the profiling of the volatile carboxylic acids and neutral compounds in blood or urine using the direct injection of the acidified sample into a gas chromatograph interfaced with a mass spectrometer by a jet separator. The non-volatile components remain at the head of the SP-1000 column while the volatile components move through the column. Up to sixty physiological samples can be analyzed before any degradation in mass spectrometer operating parameters is observed.

\section{Introduction}

Some inborn errors of metabolism are characterized by an increase in the plasma and/or urine concentration of carboxylic acids. Metabolic disorders such as propionic acidemia [1], methylmalonic aciduria [2,3], maple syrup urine disease [4], isovaleric acidemia [4] and glutaric acidemia type II $[5,6]$ show increased concentrations of volatile carboxylic acids in blood and/or urine. Gas chromatography/mass spectrometry (GC/MS) represents the current method of choice for the profiling of volatile carboxylic acids $[7,8]$. This method requires the isolation of carboxylic acids from physiological fluids by vacuum distillation [6], extraction [9.10], silicic acid absorption [11] or ion exchange chromatography [12] and conversion to the oxime-

* This work was supported by the Michigan Department of Mental Health Genetic Screening Program. Grant C376 for the March of Dimes, Grant AM 25548 from the National Institutes of Health, and a grant from the Developmental Disabilities Council of Michigan, USA.

** To whom correspondence should be addressed. 
TMS, TMS or methyl ester derivative prior to injection into the gats chromatograph/mass spectrometer [7.8]. Isolation and derivatization of carboxylic acids may result in significant losses of the more volatile compounds. and mav result in compound decomposition because of the instability of the derivatized carboxylic acid [7.8]. In addition, derivatization may afford multiple products [7.8]. The isolation and derivatization processes preclude the detection and identification of volatile neutral compounds which may be of clinical significance [1 1.1.3].

We have recently developed a rapid procedure for the gas chromatographic profiling of volatile carboxylic acids and neutral compounds in plasma and urine [14] which used direct injection of the acidified sample into a gas chromatograph with flame ionization detection. We now report the adaptation of this technique to GC/MS employing direct injection of acidified physiological fluids into a gas chromatograph interfaced to a mass spectrometer by a jet separator. The mass spectrometer facilitates peak identification and quantification by total ion abundance (TIA) and/or selected ion monitoring (SIM).

\section{Materials and methods}

\section{Materials}

All carboxylic acid standards were purchased either from Sigma Chemical Co. (St. Louis, MO, USA) or from Aldrich Chemical Company (Milwaukee, WI, USA) and were used as received.

\section{Equipment}

A Hewlett Packard 5995B GC/MS (Palo Alto, CA, USA) equipped with a $10 \%$ SP-1000/1\% $\mathrm{H}_{3} \mathrm{PO}_{4}$ on 100/200 Chromosorb WAW (1.83 $\mathrm{m} \times 2 \mathrm{~mm}$ i.d.) glass GC column (Supelco, Inc., Bellefonte, PA, USA) was used for all determinations.

The SP-1000 column was conditioned at $190^{\circ} \mathrm{C}$ with a helium flow rate of 20 $\mathrm{ml} / \mathrm{min}$. Periodic injection of a $1 \%$ formic acid solution was repeated until a stable baseline resulted (1-2 days).

\section{Analytical procedure}

Urine To $1.00 \mathrm{ml}$ of urine was added $10 \mu \mathrm{l}$ of a $1.02 \mathrm{mg} / \mathrm{ml}$ trimethylacetic acid [11] (internal standard) solution and the $\mathrm{pH}$ of the sample was adjusted to 1.0 by the addition of $1 \mathrm{~mol} / 1 \mathrm{HCl}$. A $1-\mu \mathrm{l}$ aliquot was injected on to the SP-1000 column. GC conditions: column, $150^{\circ} \mathrm{C}$ isothermal; injector, $230^{\circ} \mathrm{C}$; flow rate, $20 \mathrm{ml} \mathrm{Hc} / \mathrm{min}$. Mass spectrometer; transfer line, $280^{\circ} \mathrm{C}$; ion source, $200^{\circ} \mathrm{C}$; mass analyzer, $230^{\circ} \mathrm{C}$. The usual analysis time was $45-55 \mathrm{~min}$.

Plasma To $1.00 \mathrm{ml}$ of $1 \mathrm{mmol} / \mathrm{l} \mathrm{HCl}$ was added $10 \mu \mathrm{l}$ of a $1.02 \mathrm{mg} / \mathrm{ml}$ trimethylacetic acid solution (internal standard). A $10-\mu 1$ aliquot was mixed with 10 $\mu 1$ of plasma and a $1-\mu \mathrm{l}$ aliquot was injected on to the SP-1000 column. The GC/MS parameters were the same as those used for urine samples. 
The method of standard additions was used to quantify volatile carboxylic acids. Peak height ratio (analyte peak height/internal standard peak height) was determined from the total ion abundance chromatogram or from the selected ion chromatogram, thus permitting either to be used for quantification. In the selected ion mode, the mass $(\mathrm{m} / \mathrm{z})$ of the base peak in the mass spectrum of each acid was the ion used for quantification.

The day-to-day and run-to-run peak height variation was determined without an internal standard using both total ion abundance and selected ion monitoring. The $\mathrm{GC} / \mathrm{MS}$ parameters were kept constant during these determinations.

\section{Results and discussion}

Figure 1 shows the total ion abundance chromatogram of a standard solution that is used to determine when a new SP-1000 column is fully conditioned and to monitor column performance. Peaks were identified by their relative retention time (trimethylacetic acid internal standard) and their mass spectrum. 2-Methylbutanoic acid and 3-methylbutanoic acid coelute but they can be differentiated by their mass spectra and thus by selected ion monitoring. A McLafferty rearrangement [15] yields an $m / z 60$ base peak in the mass spectrum of 3-methylbutanoic acid while the same rearrangement yields an $m / z 74$ base peak for 2-methylbutanoic acid.

A comprehensive listing of all volatile carboxylic acids detected and identified in plasma or urine samples is presented in Table I. The relative retention time, approximate total ion abundance detection threshold (peak height is twice the noise) and the major fragments observed in the mass spectrum are included for each compound. Because of the injection port temperature $\left(230^{\circ} \mathrm{C}\right)$, it was anticipated that hydroxycarboxylic acids would undergo an acid catalyzed thermal dehydration to the corresponding unsaturated carboxylic acid $[16,17]$. However, dehydration did not occur and the hydroxycarboxylic acids were detected unchanged.

The total ion abundance chromatogram of a normal urine and plasma sample is shown in Fig. 2. Formic acid is a syringe contaminate (see 'Materials and Methods')

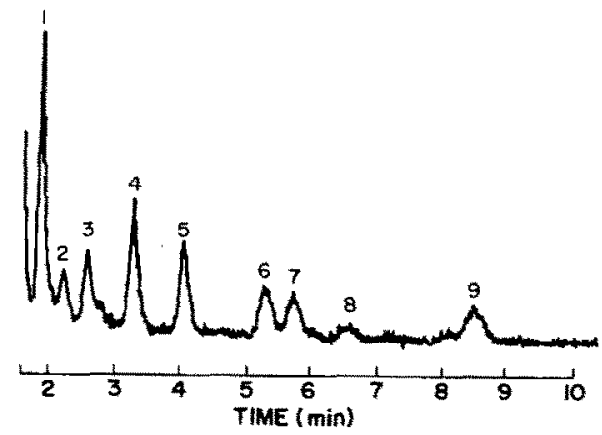

Fig. 1. Total ion abundance chromatogram of a standard volatile carboxylic acid mixture. 1. Formic acid; 2, propanoic acid; 3 , isobutyric acid; 4 , butanoic acid; $5,2+3$-methylbutanoic acid; 6 , pentanoic acid; 7 , crotonic acid; $8, \beta$-methylcrotonic acid; 9 , hexanoic acid. 
and is found in every chromatogram. Lactic acid is a normal plasma compontent and has been detected in every plasma profile. Volatile neutral and phenolic compounds are observed (Fig. 3) in many of the profiles (normal and abnormal) of physiological fluids [13]. The volatile neutral and phenolic compounds in physiological fluids mav be of dietary or drug origin.

However, Zlatkis et al [13] reported a direct relationship between urinary and/or serum volatile alcohol and carbonyl compound concentrations and diabetes mellitus.

TABLE 1

Volatile carboxylic acids in plasma and urine

\begin{tabular}{|c|c|c|c|}
\hline Acid & RRT & $\begin{array}{l}\text { Detection limit } \\
(\mu \mathrm{g} / \mathrm{ml})\end{array}$ & Mass spectrum $(m / z)$ \\
\hline Hydroxyacetic (glycolic) & 0.49 & $\mathrm{nd}^{\mathrm{b}}$ & 31 (base) \\
\hline Propanoic & 0.81 & 15 & 75 (base) $73,57,45$ \\
\hline $\begin{array}{l}\text { 2-Methylpropanoic } \\
\text { (isobutyric) }\end{array}$ & 0.93 & 10 & 73,43 (base), 41 \\
\hline $\begin{array}{l}\text { Trimethylacetic } \\
\text { (internal standard) }\end{array}$ & 1.00 & nd & $102.87,57$. (hase) 45 \\
\hline 3-Hydroxypropanoic & 1.16 & nd & 72 (base, 55,45 \\
\hline Butanoic & 1.17 & 10 & 73,60 (basc) 45 \\
\hline 2-Methylbutanoic & 1.46 & 10 & 74 (base) $, 73,68,57$ \\
\hline $\begin{array}{l}\text { 3-Methylhutanoic } \\
\text { (isovaleric) }\end{array}$ & 1.46 & 10 & 60 (base) 45,42 \\
\hline 4-Hydroxybutanoic & 1.60 & nd & $86,56,42$ (hase), 41 \\
\hline Pentanoic & 1.89 & 10 & 73,60 (base), 45 \\
\hline 2-Buteneoic (crotonic) & 2.06 & 10 & 86.67 .68 .41 (hase) \\
\hline 2-Ketopropanoic (pyruvic) & 2.13 & 150 & $88,56,44,43$ (base) \\
\hline $\begin{array}{r}\text { 3-Methyl-2-buteneoic } \\
(\beta \text {-methylcrotonic) }\end{array}$ & 2.37 & 10 & 100 (base) .53 .43 .41 \\
\hline $\begin{array}{l}\text { 2-Methyl-2-buteneoic } \\
\text { (tiglic) }\end{array}$ & 2.82 & 15 & 100,55 (base) 45 \\
\hline Hexanoic & 3.00 & nd & 73.60 (base) .45 .43 \\
\hline 4-Ketopentanoic & 3.10 & 100 & $99.56,55.43$ (base) \\
\hline 2-Ketopentanoic & 4.10 & 200 & 71. 45.43 (hate) \\
\hline $\begin{array}{l}\text { 2-Keto-3-methyl- } \\
\text { pentanoic }\end{array}$ & 4.43 & nd & 57 (base) 45,41 \\
\hline $\begin{array}{l}\text { 3-Keto-2-methyl- } \\
\text { pentanoic }\end{array}$ & 4.68 & nd & 102,73 (basc) 55,41 \\
\hline $\begin{array}{l}\text { 2-Keto-4-methyl- } \\
\text { pentanoic }\end{array}$ & 4.71 & nd & 57 (base), 45. 43.41 \\
\hline Succinic & 7.01 & nd & 56 (hase) 45.44 \\
\hline $\begin{array}{l}\text { 2-Hydroxy-2-methyl- } \\
\text { propanoic }\end{array}$ & 7.87 & nd & $59,44,43$ (base) \\
\hline $\begin{array}{l}\text { 2-Hydroxypropanoic } \\
\text { (lactic) }\end{array}$ & 9.26 & 150 & 45 (base), 44.43 \\
\hline 3-Hydroxybutanoic & 11.77 & 20 & $71,60,43$ (base) \\
\hline 2-Hydroxybutanoic & 13.81 & nd & 59,44 (base), 41 \\
\hline
\end{tabular}

a Total ion abundance under normal profile conditions.

b Not determined. 
respiratory viral infection and renal insufficiency. Burke et al [18] have profiled the urinary volatile compounds from phenylketonuria, maple syrup urine disease and isovaleric acidemia patients. They are able to differentiate these diseases by the major volatile compounds founds in the urinary profile. The relationship between the concentration of volatile neutral and phenolic compounds in physiological fluids and metabolic abnormalities needs further investigation. The volatile neutral and
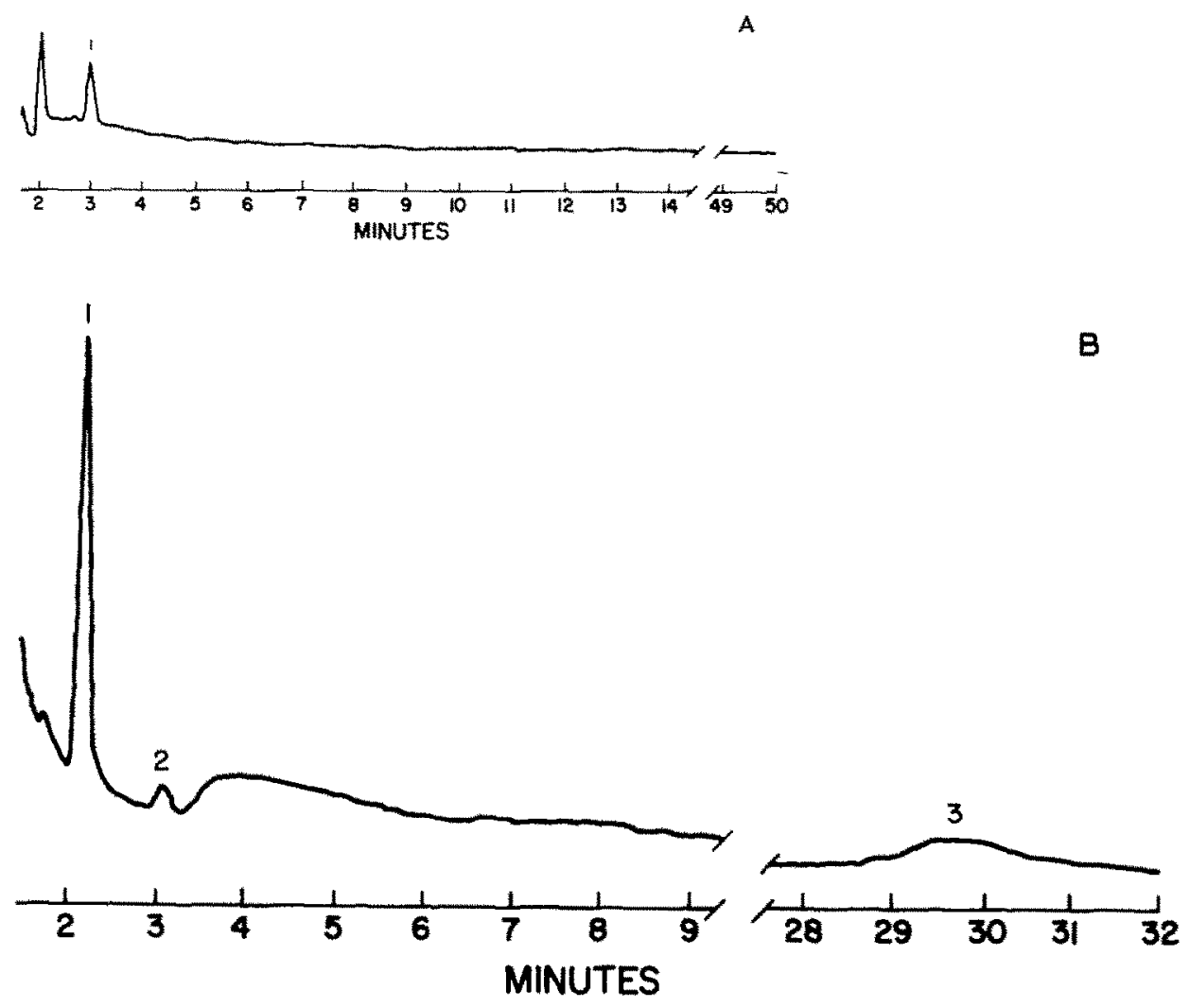

Fig. 2A. Total ion abundance chromatogram of a normal urine sample. Peak 1 is the internal standard. B. Total ion abundance chromatogram of a normal plasma sample. 1. formic acid; 2, internal standard; 3 , lactic acid.

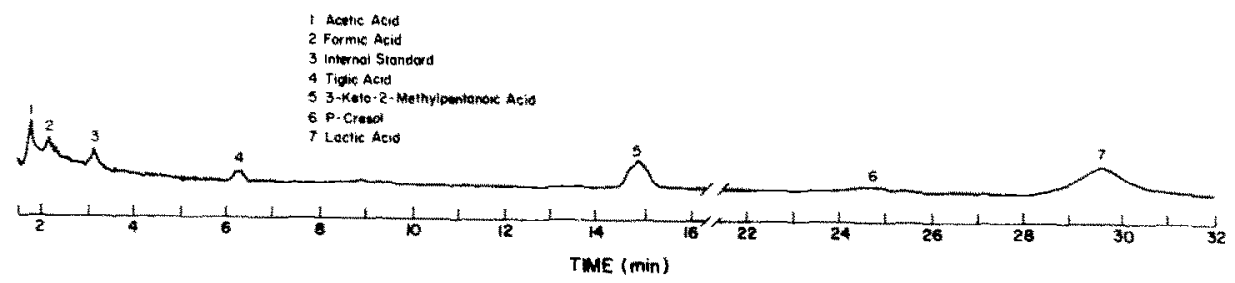

Fig. 3. Total ion abundance chromatogram of an abnormal uritre sample. 1, Acetic acid; 2, formic acid; 3 , internal standard; 4, tiglic acid; 5, 3-keto-2-methylpentanoic acid; 6, $p$-cresol; 7, lactic acid. 
phenolic compounds we have identified in profiles of physiological fluids are listed in Table II.

The total ion abundance chromatogram of an abnormal urine sample is shown in Fig. 3. Lactic acid, tiglic acid (2-methyl-2-buteneoic acid) and 3-keto-2-methylpentanoic acid are not detectable in a normal urine profile. The presence of 3-keto-2methylpentanoic acid in this urine was postulated to be due to valproic acid therapy. Neither the 3-keto-2-methylpentanoic acid peak nor the tiglic acid peak was present in a urine sample obtained $72 \mathrm{~h}$ after removal of the patient from valproic acid. However, the lactic acid peak remained. Tiglic acid may have been produced from the metabolism of 3-keto-2-methylpentanoic acid.

The total ion abundance chromatograms of urine samples from a child with vitamin $\mathrm{B}_{12}$-responsive methylmalonic aciduria are shown in Fig. 4 . The $230^{\circ} \mathrm{C}$ injection port of the gas chromatograph quantitatively decarboxylates methyl-

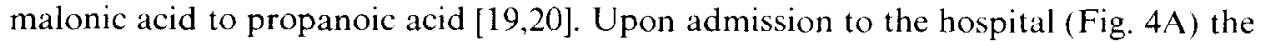
child's urinary methylmalonic acid excretion was $6.7 \mathrm{mg} / \mathrm{mg}$ creatinine (35.0 $\mu \mathrm{mol} / \mathrm{ml}$ ). After 48 -h of vitamin $B_{12}$ therapy, (Fig. $4 B$ ) the urinary methylmalonic acid excretion was $1.0 \mathrm{mg} / \mathrm{mg}$ creatinine $(5.1 \mu \mathrm{mol} / \mathrm{ml})$. Normal urinary methylmalonic acid excretion for a child of the same age is $30.6 \pm 14.2 \mu \mathrm{g} / \mathrm{mg}$ creatinine [7].

The volatile carboxylic acids in physiological fluids can be quantified directly from the total ion abundance chromatogram or by the selected ion monitoring of a second injection of the sample. Because of the specificity of the technique, selected ion monitoring affords the best results (Table III). The base peak in the mass spectrum of each carboxylic acid was the ion monitored. Peak height ratio determination (analyte peak height/internal standard peak height) using the method of standard addition was used to obtain the least squares correlation coefficients shown in Table III.

The day-to-day and the run-to-run peak height variation of a standard volatile carboxylic acid mixture was determined for both total ion abundance and selected ion monitoring (Table IV). The magnitude of the variability for each procedure shows the need of an internal standard for quantification.

TABLE II

Volatile neutral and phenolic compounds found in physiological fluids

\begin{tabular}{lcc}
\hline Compound & RRT & Mass spectrum $(\mathrm{m} / \mathrm{z})$ \\
\hline 2-Furaldehyde & 0.75 & 96,95 (base) $, 84,54,42,39$ \\
Pentanal & 0.80 & $57,45,44$ (base), 43 \\
Catechol & 1.18 & 110 (base) $, 109,53,51$ \\
Cyclohexanone & 2.13 & $98($ base $), 70,69,55.43$ \\
Benzyl alcohol & 3.45 & $109,108,107,77($ base $)$ \\
Phenol & 5.48 & $94($ base $), 66,65$ \\
$p$-Cresol & 7.64 & 108,107 (base) $, 56,42,41$ \\
Benzaldehyde & 12.77 & 105 (base) $, 56,55$ \\
Ethyl benzoate & 24.95 & $122,106,105$ (base) $, 94,75,74$ \\
\hline
\end{tabular}



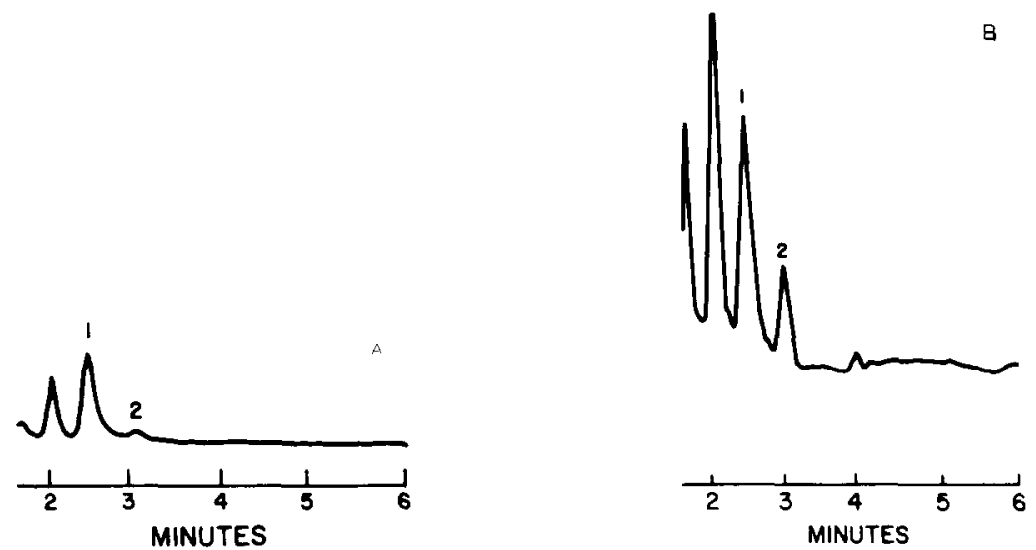

Fig. 4A. Total ion abundance chromatogram of a urine sample from a child having vitamin $\mathrm{B}_{12}$ responsive methylmalonic aciduria. Sample taken upon admission to the hospital. Peak 1, propanoic acid from methylmalonic acid (see text), $35.0 \mu \mathrm{mol} / \mathrm{ml}$; peak 2, internal standard. B. Total ion abundance chromatogram of a urine sample from the same child after $48 \mathrm{~h}$ of vitamin $\mathrm{B}_{12}$ therapy. Peak 1. propanoic acid from methylmalonic acid, $5.1 \mu \mathrm{mol} / \mathrm{ml}$; peak 2 , internal standard.

The metabolic abnormalities that can be detected by volatile carboxylic acid profiling are characterized by urine and plasma volatile carboxylic acid concentrations that are at least ten times the normal value. The detection limits of this technique (Table I) in urine dictates that any volatile carboxylic acid present in the total ion abundance chromatogram must be present in a greater than normal concentration. With the exception of lactic acid, the same is true for plasma. A small lactic acid peak (lactic acid peak height/internal standard peak hcight $\leq 1$ ) is

\section{TABLE 111}

Volatile carboxylic acid quantification: least squares correlation

\begin{tabular}{|c|c|c|c|}
\hline Name & RRT & TIA “ & $\operatorname{SIM}^{\star \prime}$ \\
\hline Propanoic & 0.81 & $r=0.98$ & $r=0.96$ \\
\hline 2-Methylpropanoic (isobutyric) & 0.93 & 0.95 & 0.98 \\
\hline 3-Hydroxypropionic & 1.16 & 0.91 & c \\
\hline Butanoic & 1.17 & 0.88 & 0.98 \\
\hline 2-Methylbutanoic & 1.46 & b & 1.00 \\
\hline 3-Methylbutanoic (isovaleric) & 1.46 & b' & 1.00 \\
\hline Pentanoic & 1.89 & 0.18 & 1.00 \\
\hline 2-Butanoic & 2.06 & 0.03 & 0.96 \\
\hline 2-Ketopropanoic (pyruvic) & 2.13 & 0.98 & 0.96 \\
\hline 2-Methyl-2-butanoic & 2.82 & 0.05 & 0.88 \\
\hline 2-Ketopentanoic & 4.10 & 0.98 & 0.95 \\
\hline 2-Hydroxypropanoic (lactic) & 9.26 & 0.98 & 0.96 \\
\hline 3-Hydroxybutanoic & 11.77 & 0.91 & 0.88 \\
\hline
\end{tabular}

a Manual peak height determination.

b Peaks coelute, thus the compound cannot be quantified by TIA profiling.

'Skewed peak. 
TABIFEIV

Peak height variability for some watile warboxyle acids"

\begin{tabular}{|c|c|c|c|c|}
\hline \multirow[t]{2}{*}{ Compound } & \multicolumn{2}{|c|}{ Run-to-Run variation $(n=5)$} & \multicolumn{2}{|c|}{ 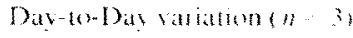 } \\
\hline & TIA & SIM & $\overline{T I A}$ & SIM \\
\hline $\begin{array}{l}\text { 2-Ketopropanoic } \\
\text { (pyruvic) }\end{array}$ & $35 \%$ & $7 \%$ & $20 \%$ & $3 " r$ \\
\hline $\begin{array}{l}\text { 2-Hydroxypropanoic } \\
\text { (lactic) }\end{array}$ & 23 & 17 & 3 & 6 \\
\hline Propanoic & 21 & 31 & 14 & 3 \\
\hline 2-Methylpropanoic & 6 & 13 & 8 & 4 \\
\hline Butanoic & 13 & 14 & 7 & 1 \\
\hline 2-Methylbutanoic & 6 & 7 & 5 & 1 \\
\hline $\begin{array}{l}\text { 3-Methylbutanoic } \\
\text { (isovaleric) }\end{array}$ & 6 & 1 & 5 & 6 \\
\hline Pentanoic & 10 & 6 & 6 & 4 \\
\hline Hexanoic: & 9 & 2 & 8 & 2 \\
\hline
\end{tabular}

"Manual peak height determination.

observed in all plasma total ion abundance profiles. Those metabolic abnormalities that are not characterized by elevated plasma or urine volatile carboxylic acid concentrations cannot be detected by this technique. These disorders must be detected by the GC or GC/MS profiling of TMS derivatized carboxylic acids.

Contamination of the mass spectrometer by physiological fluids has not been the problem we anticipated. We believe the non-volatile components of plasma and urine are held on the injector side of the SP- 1000 column and thus never enter the jet separator or the mass spectrometer. We routinely change columns and clean the jet separator after $40-50$ physiological samples have been profiled. The mass spectrometer 'down time' has not been excessive. In addition, ghost peaks have not been a problem. We routinely inject several microliters of a $1 \%$ formic acid solution on to the column after each profile. This reduces ghost peak formation and cleans the jet separator.

The rapid profiling technique described in this report provides for a markedly shortened interval between the time a sample is received and when the diagnostic information is available to the physician. In most inborn errors of carboxylic acid metabolism, a rapid and accurate diagnosis is essential if life-saving measures are to be effective. Precise identification of the defects permits the administration of cofactor therapy or the reduction of toxic dietary nutrients. The sooner these measures are initiated, the better the chance of a good outcome for the patient.

\section{References}

1 Hommes FA, Kuipers JRG, Elema JD, Jansen JF, Jonxis JHP. Propionic acidemia, a new inborn crror of metabolism. Pediatr Res 1968: 2: 519-524.

2 Oberholzer UG, Leven B, Burgess EA, Young WF. Methylmalonic aciduria: an inborn error of metabolism leading to chronic metabolic acidosis. Arch Dis Child 1967: 42: 492-504. 
3 Stokke O, Eldjarn L, Norum KR, Stein Johnson J, Halvorsen S. Methylmalonic aciduria: a new inborn error of metabolism which may cause fatal acidosis in the neonatal period. Scand J Clin Lab Invest 1967: 20: 313-328.

4 Dancis J. Levitz M. Abnormalities of branched chain amino acid metabolism (hypervalinemia. maple syrup urine disease, isovaleric acidemia and $\beta$-methylcrotonic aciduria). In: Stanbury JB. Wyngaarden JB. Fredrickson DS, eds. The metabolic basis of inherited diseases, 3rd ed. New York: McGraw-Hill, 1972: 397-410.

5 Przyrembel H, Wendel V, Becker K, Bremer HG, Bruinvis L, Ketting D, Wadman SK. Glutaric aciduria type II: report on a previously undescribed metabolic disorder. Clin Chim Acta 1976: 66: $227-239$.

6 Sweetman L, Nyhan WL, Trauner DA, Merritt A. Singh M. Glutaric aciduria type Il. J Pediatr 1980; 96: $1020-1026$.

7 Chalmers RA, Lawson AM. Organic acids in man. New York: Chapman Hall, 1982: 1-43.

8 Goodman SI, Markey SP. Diagnosis of organic acidemias by gas chromatography-mass spectrometry. New York: Alan R. Liss, Inc., 1981: 11-102.

9 Whitehead JS, Kim YS. Prizont R. A simple quantitative method to determine short chain fatty acid levels in biological fluids. Clin Chim Acta 1976; 72: 315-318.

10 McArthur B, Sarnaik AP. Quantitation of short-chain fatty acids in plasma. Clin Chem 1982: 28: $1983-1984$.

11 Bachmann C, Colombo J-P, Beruter S. Short chain fatty acids in plasma and brain: quantitative determination by gas chromatography. Clin Chim Acta 1979: 92: 153-159.

12 Gates SC, Dendramis N, Sweeley CC. Automated metabolic profiling of organic acids in human urine. Clin Chem 1978; 24: 1674-1679.

13 Zlatkis A. Brazell RS. Poole CF. The role of organic profiles in clinical diagnosis. Clin Chem 1981: 27: 789-797.

14 Buchanan DN, Bonasso F. Thoene JG. Volatile carboxylic acid profiling in physiological fluids. J Chromatogr 1983; 278: 133-138.

15 McLafferty FW. Interpretation of mass spectra, 3rd ed. Mill Valley, California: Univ. Science Books. 1980: 64 .

16 March J. Advanced organic chemistry: reactions, mechanisms and structure. New York: McGraw-Hill. 1968: 754.

17 Jellum E. Profiling of human body fluids in healthy and diseased states using gas chromatography and mass spectrometry, with spccial refcrence to organic acids. J Chromatogr 1977: 143: 427-462.

18 Burke DG, Halpern B, Malegan D, McCairns E, Danks D. Schlesinger P, Wilken B. Profiles of urinary volatiles from metabolic disorders characterized by unusual odors. Clin Chem 1983; 29: 1834-1838.

19 Frenkel EP, Kitchens RL. A simplified and rapid quantitative assay for propanoic and methylmalonic acids in urine. J Lab Clin Med 1975; 85: 487-496.

20 Van Den Berg H, Hommes FA. A rapid and sensitive method for the determination of short chain fatty acids in serum. Clin Chim Acta 1974; 51: 225-232. 